\title{
DISFUNÇÃO ERÉTIL E FENOMENOLOGIA: O CORPO VIVIDO EM SEUS CONTORNOS DIACRÍTICOS
}

\author{
Erectile Dysfunction and Phenomenology: The Lived Body in Its Diacritic Contours \\ Disfunción de la Erección y Fenomenología. El Cuerpo Vivido en sus Contornos Diacríticos
}

FABIANA De ZoRZI

Georges Daniel Janja Bloc Boris

\begin{abstract}
Resumo: O objetivo deste artigo é discutir a experiência da disfunção erétil sob uma perspectiva fenomenológica e a linguagem estabelecida pelo corpo vivido nesta experiência. Para tanto, selecionamos entrevistas fenomenológicas realizadas e analisadas com dois entrevistados. O método fenomenológico empregado foi a análise dos contornos diacríticos. Como contornos diacríticos, compreende-se as enunciações produzidas pelo corpo vivido. Eles dão forma à experiência e servem como um código de acesso à compreensão do fenômeno. Os dados obtidos por meio da análise dos contornos diacríticos permitiram explicitar a "forma" como cada sujeito vive a experiência da disfunção erétil, sendo possível contemplar diferentes enunciações dos sujeitos, como choros, conversas internas, risos, fungadas, dicotomias de expressões, ressonância de fonemas, fonemas repetidos, enfim, enunciações em estado bruto que deram cor e movimento particular a cada entrevista, viabilizando a compreensão da estrutura das suas experiências. Através delas, pudemos considerar que a dificuldade ou ausência de ereção faz parte de um campo relacional deste sujeito, em que a coexistência da parceira é fator fundamental no que condiz à disfunção erétil.
\end{abstract}

Palavras-chave: Disfunção erétil; Contornos diacríticos; Subjetividade masculina; Fenomenologia; Merleau-Ponty.

Abstract: The purpose of this article is to discuss the experience of erectile dysfunction through a phenomenological perspective and language established by lived body in this experience. We used phenomenological interviews conducted and analyzed with two men. The phenomenological method employed to analyze was the diacritic contours. How diacritic contours, understands the utterances produced by the lived body. They shape the experience and serve as an access code to the understanding of the phenomenon. The data obtained by the analyses of the diacritic contours was enabled to explain the "form" as each subject is experiencing erectile dysfunction, which can include different utterances of subjects, as crying, internal conversations, laughs, sniffles, dichotomies expressions, phonemes resonance, repeated phonemes, finally, utterances in their raw state which gave particular color and movement to each interview, enabling the understanding of the structure of their experiences. Through that, we can consider the erection lack or difficulty is part of this personal relational field in which his partner coexistence is a fundamental factor in the erectile dysfunctional.

Keywords: Erectile dysfunction; Diacritics contours; Masculine subjectivity; Phenomenology; Merleau-Ponty.

Resumen: El propósito de este artículo es discutir la experiéncia de la disfunción eréctil bajo una perspectiva fenomenológica y el lenguaje establecido por el cuerpo vivido en este experimento. Seleccionamos investigaciones fenomenológicas realizadas y analizadas con dos hombres. El método fenomenológico empleado fue el análisis de los contornos diacríticos. Como contornos diacríticos, se comprende los enunciados producidos por el cuerpo vivido. Ellos dan forma a la experiencia y sirven como un código de acceso a la comprensión del fenómeno. Los datos obtenidos mediante el análisis de los contornos diacríticos permitieron explicar la "forma", la manera como cada sujeto vivencia la disfunción eréctil, siendo posible contemplar distintas expresiones, tales como el lloro, conversaciones internas, risas, lloriqueos, dicotomías de expresiones, resonancia de fonemas, fonemas repetidos, y finalmente, enunciaciones en el estado bruto que dieron un color y un movimiento particular a cada investigación, lo que permitieron la comprensión de la estructura de sus experiencias. A través de ellas, se considera que la dificultad o la falta de erección hacen parte de un campo relacional de este sujeto, en que la coexistencia de la pareja es un factor fundamental en consonancia con la disfunción eréctil.

Palabras-clave: Disfunción eréctil; Contornos diacríticos; Subjetividad masculina; Fenomenología; Merleau-Ponty.

"O "genital” e mesmo o "sexual” são o todo, porque eles são a carne (ou seja, não um "fenômeno" ou um “corpo fenomenal”, mas um ser de duas faces) que é o que ele é e também o que ele não é e a ser, uma abertura, uma luz no sentido em que se fala de uma luz na boca do fogo".

(Merleau-Ponty, 2007, p. 435) ${ }^{1}$

\footnotetext{
"Le "génital"et même le "sexuel" sont tout parce qu'ils sont la chair (c’est-à-dire non pas un "phénomène" ou un "corps phénomènal”, mais un être à deux faces, qui est ce qu'il est et aussi ce qu'il n'est pas et a à être, une ouverture, une "lumière" au sens où l'on parle de "lumière" dans les bouches à feu (Merleau-Ponty, 2007, p. 435).
} 


\section{Introdução}

Um dos principais museus do mundo, o Museu do Louvre, em Paris, conta com galerias de esculturas antigas desde 1642, da criação das Salas das Cariátides por Luís XIV. Para quem caminha por entre as galerias de esculturas da Grécia antiga, é possível contemplar um grande acervo de bustos de perfeitos corpos masculinos que poderiam nos remeter à virilidade do homem grego. E dentre eles também é possível a apreciação de bustos de eunucos, que retratam o espírito do homem tomado pelo amálgama dos impotentes entre os séculos XVII e XVIII. Os eunucos eram homens castrados, que tiveram o seu pênis ou seus testículos retirados, ou mesmo ambos. De origem grega, o termo eunoukhos pode ser traduzido como "guardião da cama”. A castração era utilizada na Grécia antiga para impedir a reincidência de estupros ou adultérios, como também tornar os serviçais domésticos mais dóceis e inofensivos. Sua finalidade primeira era torná-los sexualmente impotentes. Mesmo alguns homens que tiveram seus testículos retirados após a puberdade, eram "capazes de manter seu membro viril, no entanto, sem ejacular” (Duby, Ariès, Bottéro, Chaussinand-Nogaret, Corbin, Darmon, Delort, Guerrand, Lebigre, Lebrun, Le Goff, Mossé, Moulin, Rey, Roche, Salles, Sartre, Solé, Sot, Thébaud, Veyne \& Zeldine, 1991, p. 230).

Em 1587, a Igreja decretou a impotência masculina como um impedimento público. Eunucos e homens impotentes, por quaisquer outros fatores, acabaram sendo tratados, tanto pela igreja quanto pelo público com o mesmo estigma. O decreto da igreja, pelo Papa Sisto V, transformou-se em uma faca de dois gumes.

(...) as mulheres que casam voluntariamente com homens que, sob o título usurpado de marido tornam o sacramento do casamento em escárnio e se envolvem em uma imitação falsa de seus mistérios. $\mathrm{Na}$ realidade, estes casamentos constituem abomináveis refinamentos de deboche e portanto são em si marcas do pecado e as sementes da condenação (Duby et al, 1991, p. 230) ${ }^{2}$.

Como bem contextualiza Berlinck (2008), “(...) a reconhecida existência da dor moral faz com que o fenômeno ultrapasse em muito o interesse meramente fisiológico" (p. 63). Os questionamentos do homem que sofre com disfunção erétil (DE) vão além do corpo em seu sentido restrito, atingem este homem como um todo, atravessando também as relações que estabelece. Para Freitas (2011), a partir de Merleau-Ponty, adoecer não significa

\footnotetext{
“...les femmes épousent volontiers ces hommes qui, sous le titre usurpé de mari tournent le sacrement du mariage en dérision et se livrent à une imitation fallacieuse de ses mystères. En realité, ces mariages constituent d'abominables raffinements de débauche et portent en eux la marque du péché et le germe de la damnation".
}

um acometimento exclusivamente somático, "mas uma forma de estar no mundo, que inclui a dimensão corporal não apenas como efeito, mas como fonte de sentidos" (p. 154). A doença retira o homem dos movimentos aos quais está habituado e o coloca na busca do "gesto expressivo". No caso destes homens sobre os quais se debruçou a pesquisa, eles buscavam um tratamento que trouxesse o funcionamento de seus corpos de volta.

Embora alguns homens - talvez com mais informação e condições de acesso ao tratamento - consigam ser ajudados, muitos ainda hesitam em buscar ajuda por temerem ser estigmatizados socialmente. A disfunção erétil é considerada um estigma social (Falconnet \& Lefaucher,1975; Duby et al, 1991). Os homens que a experienciam muitas vezes são chamados de "impotentes", por não conseguirem dar prazer a uma mulher, ou mesmo engravidá-la (Cavalcanti \& Cavalcanti, 1992; Rodrigues Jr, 2001).

A noção de virilidade estigmatizada, bem tecida pelas questões de gênero, que delineiam o conflito entre as inevitáveis quebras de paradigma da subjetivação do masculino e o rótulo de virilidade assinado pelos homens são partes de um mundo vivido. Um mundo vivido nas construções relacionais, pelas quais não existe virilidade - um homem não nasce homem, ele se faz homem e a noção de virilidade precisa ser constantemente administrada (Falconnet \& Lefaucheur, 1979; Kimmel, 1996; Boris, 2002).

Segundo o Diagnostic and Statistical Manual V (DSM-V), por disfunção erétil entende-se a combinação ou apenas um dos sintomas a seguir, por pelo menos seis meses: dificuldade na obtenção de uma ereção durante a atividade sexual; dificuldade em manter uma ereção até a conclusão da atividade sexual; e/ou diminuição acentuada na rigidez erétil, que interfere na atividade sexual (APA, 2012). Ter dificuldades eventuais em atingir a ereção não é considerado disfunção erétil. Conforme diversos urologistas, os homens que mais apresentam dificuldade em um bom prognóstico do tratamento de disfunção sexual são os que sofrem de disfunção erétil de ordem psicogênica. Ainda, segundo um estudo clínico realizado com homens diagnosticados com disfunção erétil, Grassi (2004) conclui que

(...) geralmente eles não são impotentes, nem têm DE em suas masturbações. Quem já ouviu a descrição de um impotente a respeito de como se masturba, do que lança mão para atingir a ejaculação, sabe que, nesse preciso instante, nada o diferencia do mais viril dos homens. O problema é “operar” esta fantasia com um outro, aí tudo se complica, trata-se de um problema do amor (p. 258). 


\section{O corpo vivido e a coexistência com o feminino: possíveis contribuições de Merleau-Ponty à dis- função erétil}

Na Fenomenologia da Percepção, Merleau-Ponty (1945/2006), um fenomenólogo francês que desenvolveu um capítulo inteiro sobre a questão do corpo e da sexualidade, traz algumas contribuições para o tema fundamental deste artigo. Para ele, "quase sempre concebe-se a afetividade como um mosaico de estados afetivos, prazeres e dores fechados em si mesmos, que não se compreendem e só podem explicar-se por nossa organização corporal” (p. 213-214). Ou seja, para se compreender uma experiência, é fundamental considerar o entrelaçamento entre o vivido e o corpo. Neste capítulo, Merleau-Ponty (1945/2006) destaca que existe "uma ‘compreensão' erótica que não é da ordem do entendimento, (...) o desejo compreende cegamente, ligando um corpo a um corpo" (p. 217). Percebemos que, nesta passagem, Merleau-Ponty aponta para um desejo e para uma experiência de corpo em relação, para uma intercorporeidade. O que se torna evidência não é a consciência, mas a experiência do meu corpo assediando ou sendo assediado por outro corpo.

Com a noção de corpo vivido de Merleau-Ponty, é possível sairmos de um olhar dicotômico, nos dando subsídio para compreender um corpo em relação e que é constituído por múltiplos contornos (Merleau-Ponty, 1966/1996). Merleau-Ponty (2001/2006) sugere uma intersubjetividade sobre as formas de se relacionar não só com outrem, mas sempre levando em consideração a sua relação com o seu próprio corpo, que não é "só um corpo sensorial, mas também um corpo portador de técnicas, estilos e condutas" (p. 542) atravessado por uma culturalidade que lhe fornece certa fisionomia.

No decorrer do desenvolvimento de sua noção de intersubjetividade, Merleau-Ponty compreende que a percepção não é apenas uma recepção, ela envolve coexistência e apreensão da intencionalidade de outrem (Coelho Jr, 2003). Não se resume a uma construção no sentido intelectual, porém, a uma cooperação. Quando nos referimos a múltiplos contornos, nos deportamos às expressões às quais o corpo é capaz de manifestar, e estas só coexistem a partir de sua relação com o mundo e no mundo.

Merleau-Ponty formula seu conceito de intersubjetividade, no sentido de uma experiência perceptiva comum, de uma co-operação, e concebe o mundo percebido como aquele das imbricações inevitáveis entre corpos e coisas, corpos e outros corpos (Coelho Jr, 2003). Trata-se de uma impossibilidade de pensar-se em uma "realidade objetiva”. O outro que percebemos não é o outro com tal, mas como eu o percebo na minha coexistência com ele. A percepção é um movimento ativo, no sentido de que cada sujeito é um criador de sentidos, implicando e sendo implicado pela percepção de outrem. Com as próprias palavras de Merleau-Ponty (2001/2006):
(...) a percepção de outrem não é apenas a operação dos estímulos exteriores, mas também depende em grande parte do modo como estabelecemos nossas relações com os outros antes dessa percepção: ela tem raízes em todo o nosso passado psicológico; cada percepção de outrem nunca é mais que uma modalidade momentânea. Portanto, não se trata de pura recepção de certo conteúdo que seria dado tal qual, mas há sempre uma relação mais profunda, relação de coexistência com o aspecto de outrem que se apresenta (p. 545-546).

Compreender a experiência vivida da DE, portanto, também implica em compreender a noção de estrutura configurada por Merleau-Ponty (1945//2006). A disfunção erétil jamais irá acontecer, senão em coexistência com outrem, condição esta, também corroborada pelos estudos clínicos de Grassi (2004). A noção de corporeidade toma lugar do corpo meramente objetivo e ele ganha uma compreensão que se estende para além do sujeito. O nosso objetivo aqui converge ao de Merleau-Ponty, no sentido de olhar para o corpo como experiência, com seus múltiplos contornos, e na linguagem estabelecida pelo corpo vivido nesta experiência. Para tanto, recorremos a Merleau-Ponty (1995/2006), a sua obra A Natureza, em que o autor aponta para uma linguagem tácita, em que a forma com que algo é expresso, pode ser compreendida por si mesma, ao passo em que tento decodificar os seus movimentos.

Um órgão móvel dos sentidos (o olho, a mão) já é uma linguagem porque é uma interrogação (movimento) e uma resposta (percepção como Erfüllung ${ }^{3}$ de um projeto), falar e compreender. É uma linguagem tácita: a percepção de outrem no-lo mostra bem, em que temos a apreensão de uma fisionomia moral (assinatura, jeito, semblante) sem o conhecimento das categorias que parecem estar subentendidas nessa compreensão: o dado aparece registrado num certo código, com base num certo sistema [...] assim como as palavras ouvidas me aparecem contra o fundo de um certo sistema fonemático e semântico, que ainda não conheço posto que a lingüística está por fazer (p. 341-342).

Assim como um pintor projeta sua expressividade na tela, a "forma" como o sujeito expressa-se acerca da sua experiência vivida pode fornecer-nos importantes dados para a compreensão da DE como fundamentalmente uma dialética. Alhures, Merleau-Ponty (1962/2007) explica que o corpo,

(...) por seus "campos sensoriais", por toda sua organização, ele está como predestinado a se conformar aos aspectos naturais do mundo. Mas como corpo ativo, à medida que ele é capaz de gestos, de expressão e enfim

«realização», conforme Merleau-Ponty. 
de linguagem, ele se reenvia sobre o mundo para o significar... os fonemas, sem ter ainda um sentido por si mesmos, eles desde já possuem valor diacrítico, eles anunciam a constituição de um sistema simbólico capaz de redesenhar um número infinito de situações. Eles são uma primeira linguagem. E reciprocamente a linguagem pode ser tratada como uma gesticulação de tal forma variada, precisa, sistemática, e capaz de retomadas tão numerosas, que a estrutura interna do enunciado não pode finalmente convir senão a uma situação mental à qual ele responde e da qual se torna signo sem equívoco (p. 287).

Tomaremos como ponto de partida o sentido de fonema como o valor que distingue o som da voz humana, de expressão e a forma de exprimir algo (Houaiss, 2001). O diacrítico, por sua vez, é uma acentuação que confere um novo significado para o fonema. Do grego, vem do verbo diacrino, formado do elemento grego dia: através de, por meio de; e crino: separar, decidir, distinguir, discernir. Poderíamos, portanto, compreender o diacrítico aqui, como a acentuação dada ao fonema, a acentuação que cada sujeito remete às suas expressões (Houaiss, 2001).

Tanto quanto a fala, elucida Merleau-Ponty (1945/2006), também o sotaque, o tom, os gestos, a fisionomia, são importantes expressões para o alcance de sua maneira de ser fundamental. Para o alcance da compreensão do corpo vivido na disfunção erétil, faremos uso do recorte de duas entrevistas fenomenológicas da pesquisa "Os Múltiplos Contornos do Corpo Vivido na Disfunção Erétil: uma Perspectiva Fenomenológica" (Projeto CAAE 0291.0.037.000-11, aprovado em 03/08/11 pelo Coética/ Unifor) acessando a forma, no sentido diacrítico, com que Jean e Claude enunciam as suas experiências, por meio de seus múltiplos contornos (Merleau-Ponty, 1966/1996; Moreira, 2004).

Compreendemos a forma circunscrita pelos sujeitos na entrevista, como um código de acesso, em que, a partir de Merleau-Ponty (1945/2006),

A expressão estética confere a existência em si àquilo que exprime, instala-o na natureza como uma coisa percebida acessível a todos ou, inversamente, arranca os próprios signos - a pessoa do ator, as cores e a tela do pintor - de sua existência empírica e os arrebata para um outro mundo (p. 248).

Trata-se de compreendermos a DE, também, como uma linguagem, como uma das formas de tangencias do corpo vivido, discernido e atravessado por sua existência, ao mesmo nível da obra de arte, ou da palavra falada.

Devido à postura da primeira autora, como gestalt-terapeuta, estar intimamente vinculada ao processo da pesquisa, para a demarcação das expressões e os tons enunciantes, ela optou pelo uso das noções de experiência e percepção estéticas sugeridas por Alvim (2007).
Alvim (2007) considera "a experiência do terapeuta uma experiência estética, que busca a verdade ou essência do objeto, assim como é dada imediatamente no sensível, e que toma como ponto de partida a corporeidade" (p. 135). Ela acredita que a relação entre corporeidade e experiência estética aconteça na experiência do corpo como principal veículo de sua expressão.

É necessário que o pesquisador, como enunciatário, olhe para o bruto da experiência, olhe ao sujeito enunciador com os olhos do sensível, ou seja, de uma forma admirativa, através de uma percepção atenta e interessada e busque na expressão do corpo vivido, através de uma percepção estética, a matéria-prima para o acesso ao expresso, ao que o sujeito enunciador é capaz de imprimir na entrevista. Alvim (2007) propõe que se utilizem critérios estéticos para o alcance do objeto estético. A transformação requer do pesquisador "um olhar que se aproxime de uma experiência estética” (p. 140), como do admirador diante de uma obra de arte em relação "à sensação: brilho, harmonia, fluidez, à elasticidade das figuras em sua relação com o fundo" (p. 140).

Conforme vimos anteriormente, a "forma" que as expressões desenvolvem nos remete mais intimamente ao significado das enunciações. E, neste sentido, é importante ressaltar uma nota de agosto de 1959, em que MerleauPonty (1964/2009) esclarece que, a analogia dentre codificação e decodificação é válida, porém sob a condição de discernir "a fala e os seus sistemas diacríticos 'compreensíveis' sob a informação" (p. 189). Neste sentido, a partir da fenomenologia de Merleau-Ponty (1964/2009) e com um refinamento em Alvim (2007), estas expressões estão nomeadas aqui, como contornos diacríticos (De Zorzi, 2012). Esta não é uma expressão usada por Merleau-Ponty, mas foi assinalada aqui como forma de ratificarmos a experiência bruta que acompanha as expressões, ou ainda, a acentuação dada por cada sujeito no percurso da entrevista. Os contornos diacríticos são a composição dos gestos, silêncios, tons de voz, risos e enunciações deixadas como rastros ou imprimidas pelo sujeito enunciador, que ainda não estão na ordem do "dar-se conta" e que dão ênfase e significação ao discurso.

Apesar de a "forma" não ser o foco central deste artigo, ela atravessou todo o escopo teórico que o sustenta, e teve uma implicação direta na coleta e análise dos dados da pesquisa. Foram selecionados doze homens com diagnóstico de disfunção erétil, em parceria com uma médica urologista que realizou o primeiro contato com eles. A coleta de dados deu-se a partir de entrevista fenomenológica com a primeira autora, fazendo uso de uma pergunta disparadora: "Como é para você viver/ conviver com a disfunção erétil?". Após a "escuta da forma", o delineamento dos "contornos emergentes", subsequentes aos "contornos significantes", foi possível uma "compreensão dialética", a qual cedeu um recorte ilustrativo ao objetivo deste artigo: discutir a experiência da disfunção erétil sob uma perspectiva fenomenológica e 
a linguagem estabelecida pelo corpo vivido nesta experiência. Partiremos agora, para a compreensão e análise dos contornos diacríticos que sustentam a entrevista fenomenológica de Jean e Claude.

\section{A análise dos contornos diacríticos na experiência do corpo vivido na disfunção erétil}

As partes do texto com destaque em itálico referem-se às falas dos sujeitos enunciadores. Nestas falas, alguns contornos diacríticos estarão sinalizados por sublinhado quando a ênfase tiver uma atenuação abaixo do que vinha sendo expressado.

A postura da pesquisadora variou de acordo com a "forma" com que os sujeitos enunciaram-se. Alguns tinham um discurso em terceira pessoa, como no caso de Jean. A maior parte do discurso dele foi enunciada como se o que ele vinha falando não fizesse parte dele. Quando questionado por ela, para entender a quem ele estava fazendo referência com "ele”, "o cara”, “a gente", e a um reposicionamento para primeira pessoa, Jean se perdia em seu discurso, sendo preciso retomar a pergunta inicial.

Jean é um homem casado, de 53 anos, tem dois fihos e é corretor de imóveis. A expressão do que sente é visível de muitas formas. Há uma intensidade no sentir, em expressar o que pensa utilizando diversas linguagens gestuais. Quando há indignação, esta é expressa com as mãos, porém, não só com as mãos, mas toda a extensão do braço, a voz, o olhar, enfim, o corpo todo se compõe e trabalha numa coerência daquilo que está sendo dito.

Ao longo da entrevista de Jean, pudemos perceber seus contornos diacríticos por meio de movimentos muito intensos, em que ele contorna diversas situações com risos, gargalhadas, choros, reverberações e dicotomizações de palavras. Estas acentuações, estes contornos que dão cor e movimento ao discurso de Jean, bem ilustram o quadro da sua experiência da DE, no sentido de que pouco acentuam uma fisionomia sexual ou demarcam a ausência de uma libido que "repouse sobre as potências internas do sujeito orgânico" (Merleau-Ponty, 1945/2006, p. 215). Pudemos constatar em Jean um esquema corporal em perfeito funcionamento, porém, com uma opacidade significativa na sexualidade.

Jean, apesar de uma intensidade na expressão de seus sentimentos, bem como em enunciar as suas idéias, e as suas palavras, não consegue ter ereções naturalmente, sem o uso do medicamento. Sem a medicação, suas ereções acontecem a cada quatro ou cinco meses. Para ele, o sexo se resume a muito pouco perto de toda a convivência conjugal, tomadas de decisões e cumplicidade do casal acerca das questões do dia-a-dia. No recorte do depoimento a seguir, foi possível constatar uma diminuição muito grande no tom de sua voz, que até então vinha um tanto enérgico: (...)sexo é uma hora... uma hora ou duas horas por semana... a gente não passa o tempo na cama, fazendo sexo. Então, o sexo, ele se torna uma coisa... tu vai acabando esquecendo, né, na verdade. (...) A gente vai acabando esquecendo, na verdade, porque (fungada)... haaa, e...não é o aqui... não é o, o... é... na parceria, no relacionamento, o sexo não é o primeiro lugar... o primeiro lugar é tá do lado, tá brincando, tá rindo, tá... vendo que os guris vão bem, as coisas fluindo, tudo certinho, o sexo vem depois, porque a gente não passa 24 horas na cama, né?

Tanto a "forma", bem como a fluidez nas expressões de conteúdo de Jean, são claramente identificadas, o que também se torna notório na relação dialógica da pesquisadora com Jean. Pouco foi preciso que ela interviesse no decorrer da entrevista. Contrariamente à postura adotada na entrevista com Jean, o movimento da pesquisadora, em relação a Claude ${ }^{4}$ esteve em incentivar constantemente e repetidas vezes, as frases interrompidas e descontinuadas, e, em grande parte, fazendo uso de intervenções de eco ou feedbacks para estimular a continuidade de reflexões. Após algumas reflexões, Claude se deu conta que o sentimento de não ter certeza de que, de fato, a mulher esteja sentindo prazer, é grande responsável pelo reflexo de seu desejo e consequentemente, em seu (dis)funcionamento erétil. Claude ressalta que, mesmo com o remédio, existem momentos em que não "funciona”, relacionando com aspectos cotidianos de stress e preocupações:

Só na base do remédio, se não... E assim mesmo, aquele remédio que a doutora me deu tá,...ela me disse que me dava um mais forte, né. Só que num táaa fazendo muito efeito, também..... Às vezes eu vou, já preocupado com uma coisa, outra. (...)“duns” tempos pra cá, "duns” meses pra cá, começou a... a piorar um pouco. (...) Venho me vendo, que se eu não usar o remédio, até eu usando o remédio, eu tenho medo às vezes estar numa relação, e não...

A questão da medicação aponta para uma ênfase sobre o aspecto fisiológico da DE. Neste trabalho, buscamos desconstruir esta idéia do aspecto fisiológico como único, colocando-o como um dos aspectos que constituem esta experiência tão difícil para estes homens. Apesar de falarmos de algo da ordem da sensação, do prazer, podemos recorrer à Merleau-Ponty (1945/2006) quando afirma que "não há definição fisiológica da sensação e, mais geralmente, não há psicologia fisiológica autônoma porque o próprio acontecimento fisiológico obedece às leis biológicas e psicológicas” (p. 31). Ou seja, esta sensação, este prazer, está em um corpo, está no mundo e na relação com os outros. Parece haver uma dificuldade dos

\footnotetext{
4 Claude tem 51 anos, é casado, tem um enteado e um filho, e trabalha viajando como motorista de caminhão.
} 
homens em reconhecer que a DE vai além de algo puramente biológico, sendo a medicação um bom recurso para confirmar tal compreensão.

É importante ressaltar que, no caso de Claude, as relações sexuais com a esposa aconteciam e a maior dificuldade com as ereções era com as outras mulheres. Sua esposa sequer tinha o conhecimento que Claude fazia o tratamento. Podemos afirmar também que esta é uma experiência que não é puramente individual, ela está no mundo, ou seja, como o próprio Claude aponta, está ligada a aspectos do seu mundo vivido, de sua mundaneidade. São aspectos que vão além do corpo, ou melhor, estão ligados ao caráter intercorpóreo da experiência vivida. Apesar de o motivo de Claude estar nesta entrevista ser a dificuldade de ereção, seu relato ficou focado estritamente às dificuldades conjugais, refletindo sobre o possível motivo da falta de interesse sexual da esposa. Acabou se envolvendo com outras mulheres, e, inicialmente, manifestou estar evitando o sexo fora do casamento por medo de falhar, e o que estas outras mulheres pudessem comentar a seu respeito por não ter ereção.

O "medo de falhar" ou mesmo o que os outros podem dizer ao tomarem conhecimento desta "falha", foi um dado que ganhou contorno dentre muitos dos homens entrevistados. Claude afirma que:

(...) nem... nem tô saindo mais porque eu... eu fiquei com medo, né. Chegar na hora H e não dar certo... Eu já vou com medo de passar vergonha, tudo... Medo.... ah... coisa da minha cabeça...... eu tenho medo, mesmo... porque geralmente essas outras que eu tenho, que eu saio aí fora, é tudo conhecida, né, então,... sabem que eu sou casado e tudo... e começam a falar e daí piora a situação (...) fica fofoqueando pra outra, contando "oh, fulano lá não...(...) não funcionou, não deu”.(...) Passa ou te vê e já fala... "não... fulano saiu com fulana e não... chegou lá na hora H e não... (PAUSA LONGA). (...) Não... não deu, não funcionou...”

O "não querer" da parceira aflige Claude. Ao tomar conhecimento que a esposa não quer ter relações, também perde o interesse em procurá-la e logo pensa em sair:

Inclusive a gente até... às vezes a gente conversa, mas não adianta, ela não... não quer, não... tá com dor de cabeça, ou não tá bem, e eu também não procuro, eu sei que... se não tem interesse dela, não me interessa procurar ela também.(...)... tu vai procurar, "tô com dor de cabeça, tô cansada”...(...)Eu sei que não... não me faz bem isso aí. Logo já penso em sair, procurar outra coisa, né...

Embora não tenha problemas significativos de ereção com a sua esposa, a disfunção se manifesta com as outras. Ao questionar a ele, o que seria “outra coisa”, Claude continuou seu relato reflexivo:
Mas depois aí não... Não é fácil, é bem complicado isso daí (...) eu me sinto mal às vezes se eu tô aqui procurando outra, com ela em casa, entende?(...) eu fico com, tipo um sentimento de culpa.(...) "bah, tu tem mulher em casa, que que tu tem que ficaaa...” (...) E agora, se já vou fora de casa, eu vou naquele pensamento na cabeça e no fim não... Então, nem... nem tô saindo mais porque eu... eu fiquei com medo, né. Chegar na hora $\mathrm{H}$ e não dar certo.

Embora o relato de Claude acuse uma postura de querer o prazer, mesmo que seja fora de casa, ele manifesta sentir "culpa” e não ter ereção, mesmo com o auxílio do medicamento. Todos os relatos demonstram que a rejeição feminina, ou o baixo desejo na relação sexual ecoam desfavoravelmente na experiência dos homens, não apenas acentuando a manifestação da disfunção erétil naquela relação, mas repercutindo também em um projetar futuro.

A DE atravessa de forma marcante a experiência dos homens que foram entrevistados. Diversos relatos foram ilustrativos dessas experiências e nos ajudaram a compreender o que se passa na experiência desses homens e destes corpos produtores de significações. Diante desse sintoma que se expressa, alguns homens expressaram o desejo de superar esta questão, apontando diferentes vias de superação. Claude, apesar de não indicar como uma forma de superação direta pontua a confiança na parceira como condição fundamental para a ereção acontecer:

... a relação que nem... uma mulher... pegar uma mulher fora que não, aí tu não sente carinho nenhum, alí é só... fingimento, dá pra notar que é tudo fingimento (...)E tu sabe que eu acho que isso aí tá me... o meu maior medo disso aí, também é... me acontece às vezes fico com medo, meu maior medo de falhar é por causa disso daí, se não tem da outra parte, também já fica meio... (Claude)

Claude se refere à confiança de ter certeza do que a parceira está sentindo, questionando se o "contato" e o encontro, de fato estejam acontecendo. Por outro lado, ele também se refere à confiança, no caso de não "funcionar", como uma forma, como bem ressaltam Fernandes \& Catão (2008), "que traz a ter certeza de que a parceira irá cuidar, responsabilizar-se e compartilhar sua sexualidade” (p. 40).

Vai com mais confiança vai ali que tu sabe que se der um problema que não funcionar tu não vai... ela não vai te, falar pra ninguém, não vai sair espalhando, é entre os dois só. No relacionamento fora, já com certeza, a mulher sai espalhando pro outro... (Claude).

A experiência da DE ainda possibilitou a Claude produzir um movimento de retorno a tudo o que a esposa 
"passou" (sic) ao lado dele, e a como ele gostaria que fosse esta relação:

Que fosse que nem um casal normal, né. Só que dá pra notar que ela não tem mais interesse, não adianta não.(...) Deu pra perceber a mudança inclusive da parte dela, já que qual é a mulher que vai gostar de estar na cama com um cara que... tá sempre bêbado?(...)... dá pra notar o desinteresse dela, já, né? então....... Isso aí é ruim, eu me sinto mal com isso aí, também, mas... fazer o que? Eu não posso obrigar... (...) Eu queria que em casa fosse diferente, mas não dá, não adianta... (Claude)

Freitas (2011) associa o adoecer a um estar no mundo, que, neste caso, incluiria a dimensão corporal acometida pela disfunção erétil como fonte de sentidos. A DE coloca os homens diante de suas limitações de envolvimento, da dificuldade em construir uma intimidade ou mesmo de ter uma relação sexual sem nenhum tipo de envolvimento afetivo, e isto os faz refletir acerca de suas limitações, tanto quanto, em como superá-las.

Por meio de expressões produzidas por seu corpo, por sua vez, Jean sinaliza por entre uma atenuação da tonalidade de suas cordas vocais, algo referente a este equilíbrio, questionando-se, e dando continuidade à sua reflexividade:

... é fora do contexto, essa... essa falta de virilidade, claro, tu carrega todas... todas aquelas atitudes que a gente tomou antes, pra dizer "poxa, como é que eu corrijo isso?", bom eu preciso de... preciso de me "hormonizar", outra palavra que você vai aprender comigo (RISOS). Criar hormônios novamente, pra que a coisa comece a fluir novamente. (...) De cabeça, de... de corpo, de físico, de... é... de se... de equilíbrio. Entre corpo, físico, espírito, cabeça. É preciso equilibrar essas coisas, já é muito de um lado, pouco de outro, tu não consegue fazer a coisa fluindo normal, porque o normal é o equilíbrio, é... sabe, o normal da vida (fungada), assim que eu penso, é o equilíbrio ... (Jean)

Até aqui, as falas de Jean sugerem que, enquanto os sujeitos estiverem presos a um aparato sexual que não funciona e que precisa ser revisto, estarão implicados a uma perda de movimentos. Esta perda de movimento diz respeito a um não assistir a todos os contornos de seu corpo vivido que evocam o equilíbrio de um funcionamento global. Relembrando Merleau-Ponty (1966/1996), focar um único contorno, significaria sacrificar a sua profundidade. Podemos, compreender, então, recorrendo a Moreira \& Bloc (2012), que a DE pode ser corroborada "como modo de ser global do sujeito, como funcionamento que, ao perder o movimento, está fadado a um quadro psicopatológico" (p. 8).
O corpo produtor de significações, é também abertura, é também um vir a ser, e requer um funcionamento global em equilíbrio, em que, se tratando da experiência da DE, tal funcionamento global não pode ser pensado sem a coexistência da parceira. E é neste sentido que Jean finaliza a sua fala, e a nossa entrevista, quando o questiono acerca da sua manifestação em pouco vivenciar sua sexualidade, mesmo com a possibilidade que os medicamentos oferecem, hoje:

Exatamente... mesmo com a possibilidade... porque... agora os últimos tempos... algumas mudanças, de ir pro médico, da academia, a aposta é que não há... que não precise mais do medicamento, entende? É nisso que estamos apostando. Nós deixamos de fumar juntos, nós... ahh... vamos a academia juntos, sabe... a gente está apostando nessa, nessa, nessa, nesse fator, apostando na parceria, na cumplicidade da coisa. (Jean)

Esta última fala de Jean indica que, para obter prazer em um relacionamento, se requer uma convivência, por meio da qual, o casal se permita experienciar situações diversas, inclusive, as de desprazer. Como destacam Fernandes \& Catão (2008): “O prazer é aprendido e mantido de acordo com o investimento que empenhamos em uma relação” (p. 41). A DE possibilita ao casal a apreensão de um relacionar-se de forma diferente, como pudemos acompanhar com cada um dos sujeitos entrevistados.

Diante da superação dicotômica (do entrelaçamento do corpo e a alma), e da experiência clínica, a linguagem não foi tomada aqui apenas como representação mental, mas como extensão das capacidades expressivas do corpo, assim como o gesto, com as devidas ênfases na comunicação, do entre da relação. A partir da tradição do método fenomenológico (Giorgi, 1985) e dos sistemas diacríticos de Merleau-Ponty (1964/2009), tratou-se a análise fenomenológica como uma busca da escuta da "forma", com a imbricação entre gesto e fala, ou seja, a linguagem verbal é corpórea e expressiva, tomada a partir do entendimento do corpo vivido em seus contornos diacríticos.

\section{Considerações finais}

Conforme pudemos conferir, a "forma" da enunciação torna compreensível a estrutura do funcionamento global de cada corpo vivido. Quando se utiliza uma análise baseada nos contornos diacríticos, um universo ainda mais amplo de significações se abre, por se enfatizar não apenas o conteúdo, mas também a forma como este conteúdo é manifesto. Compreender esta "forma” auxilia o pesquisador a compreender quais as enunciações estão mais carregadas de expressão/ expressividade. Trata-se de uma aproximação ao sentido e à intensidade dos fonemas. Estes que, por sua vez, ganham um caráter diacrítico, dando contornos à expressividade. Cada expres- 
sividade anuncia-se como um código de acesso, ou seja, "perceber outrem é decifrar uma linguagem” (MerleauPonty, 2006/2001, p. 551). Cabe ao pesquisador, a tarefa de olhar para estes códigos de acesso, tão singulares a cada um, de uma forma atenta e admirativa.

(...) os signos são essencialmente "diacríticos”. (...) Cada um deles exprime somente por referência a uma certa aparelhagem mental, a um certo arranjo de nossos utensílios culturais e, todos juntos, são como um formulário em branco que ainda não preenchemos, como os gestos de outrem a visar e circunscrever um objeto do mundo que não vejo (Merleau-Ponty, 1960, p. 143). ${ }^{5}$

Trouxemos aqui, portanto, uma exploração "da forma”, os contornos diacríticos de Jean e Claude, com o intuito de acessar a experiência que se remete aos seus fundos constitutivos. Os dados obtidos por meio da análise dos contornos diacríticos permitiram explicitar a forma com que cada sujeito trouxe o fenômeno da disfunção erétil, viabilizando uma compreensão da estrutura da experiência. Em outras palavras, foi dada uma maior atenção às enunciações produzidas pelos múltiplos contornos do corpo vivido, como forma de acessar o expresso genuinamente.

A fenomenologia de Merleau-Ponty nos auxiliou a compreender a DE através da dialética entre os múltiplos contornos do corpo vivido. De uma forma geral, pudemos compreender a experiência da DE como uma situação de mobilidade para o homem. E nos contornos diacríticos foi possível contemplar diferentes enunciações entre os sujeitos, como choros, conversas internas, risos, fungadas, dicotomização de palavras, ressonância em fonemas, fonemas repetidos, enfim, enunciações em estado bruto que deram cor e movimentos particulares a cada entrevista.

Pudemos compreender que o corpo está intrinsecamente aderido ao mundo, não apenas como um corpo que percebe, mas com uma abertura ao mundo, como um corpo que sente e se faz sentir, que toca e é tocado, que vê e é visto, através de processos relacionais consigo e com os outros. Há um espaço em que os dois se reconhecem, porém, o eu permanece um eu e o outro permanece o outro. A sexualidade e o desejo são a intencionalidade que ganha forma e que repousa sobre este esquema corporal. O sujeito não pode ser considerado em si, como um global, e é exatamente por isto que emerge esta abertura ao mundo, como a busca de uma melhor "forma”, de um equilíbrio.

Pudemos, ainda, pensar o corpo vivido como algo que é atravessado por múltiplos contornos que constituem a experiência da DE. O corpo possui tanto um caráter objetivo quanto subjetivo, o que afasta uma visão de partes

\footnotetext{
5 les signes, comme dit Saussure, sont essentiellement «diacritiques» (...) Chacun d'eux n'exprime que par référence à un certain outillage mental, à un certain aménagement de nos ustensiles culturels, et ils sont tous ensemble comme un formulaire en blanc que l'on n'a pas encore rempli, comme les gestes d'autrui qui visent et circonscrivent un objet du monde que je ne vois pas.
}

extrapartes fragmentada, ou mesmo de uma subjetividade pura (Merleau-Ponty, 1945/2006). Podemos considerar que a dificuldade ou ausência de ereção faz parte de um campo relacional deste sujeito. Assim como também podemos corroborar com Merleau-Ponty (2001/2006), no sentido de que uma alteração em um corpo vivido pode implicar na mudança de outro corpo vivido, pois este é um corpo em relação e que faz parte do mundo como intercorporeidade. A coexistência da parceira é fator fundamental no que condiz à disfunção erétil.

\section{Referências}

Alvim, M. B. (2007). Experiência estética e corporeidade: fragmentos de um diálogo entre gestalt-terapia, arte e fenomenologia. Estudos e Pesquisas em Psicologia (UERJ), 7(1), 138-146.

APA - American Psychiatric Association (2012). Diagnostic and statistical manual of mental disorders (5 th ed.). consulta on-line http://www.dsm5.org/Pages/Default.aspx

Berlinck, M. T. (2008). Psicopatologia Fundamental. São Paulo: Escuta.

Boris, G.D. J.B. (2002). Falas de homens: A Construção da Subjetividade Masculina. São Paulo: Annablume.

Cavalcanti, R. \& Cavalcanti, M (1992). Tratamento Clínico das Inadequações Sexuais. São Paulo: Roca.

Coelho Jr, N. E. (2003). Da intersubjetividade à intercorporeidade: contribuições da filosofia fenomenológica ao estudo psicológico da alteridade. Psicologia USP, 14(1), 185-209.

De Zorzi, F. (2012). Os Múltiplos Contornos do Corpo Vivido na Disfunção Erétil: uma Perspectiva Fenomenológica. Dissertação de Mestrado, Fortaleza, UNIFOR.

Duby, G., Ariès, P., Bottéro, J., Chaussinand-Nogaret, G., Corbin, A., Darmon, P., Delort, R., Guerrand, R., Lebigre, A., Lebrun, F., Le Goff, J., Mossé, C., Moulin, A., Rey, M., Roche, D., Salles, C., Sartre, M., Solé, J., Sot, M., Thébaud, F., Veyne, P.\& Zeldine, T. (1991). Amour et sexualité en Occident. Paris: Société d'Éditions Scientifiques.

Falconnet, G. \& Lefaucher, N. (1975). La fabrication des mâles. Paris: Éditions du Seuil.

Fernandes, C.C. \& Catão, E. C. (2008). O prazer sexual do homem e da mulher. Psique Especial Ciência \& Vida, 9, 38-41.

Freitas, J. (2011). Corpo e Subjetivação: reflexões sobre uma possível contribuição da fenomenologia à psicologia. Em: Maria V.F. Cremasco (Org). O sofrimento humano em perspectiva. Enfoques psicológicos (p. 143-158). Curitiba: Editora CRV.

Giorgi A. (1985). Sketch of a psychological phenomenological method. In: A. Giorgi (Org.). Phenomenological and psychological research [pp. 8 -22]. Pittsburgh, PA: Duquesne University Press.

Grassi, M. V. F. C. (2004). Psicopatologia e disfunção erétil. São Paulo: Escuta. 
Houaiss, A. (2001). Dicionário Houaiss da Língua Portuguesa. Rio de Janeiro: Objetiva.

Kimmel, M. (1996). Manhood in America. A cultural history. New York: The Free Press.

Merleau-Ponty, M. (1996). La doute de Cézanne. In Sens et non-sens [pp. 13-32]. Paris: Éditions Gallimard. (Original publicado em 1966).

Merleau-Ponty, M. (2006). Fenomenologia da Percepção. São Paulo: Martins Fontes (Original publicado em 1945).

Merleau-Ponty, M. (2006). Psicologia e Pedagogia da Criança. São Paulo: Martins Fontes (Original publicado em 2001).

Merleau-Ponty, M. (2006). A Natureza. São Paulo: Martins Fontes (Original publicado em 1995).

Merleau-Ponty, M. (2007). New Working Notes from the Period of the Visible and the Invisible. In The Merleau-Ponty Reader. Edited by Ted Toadvine and Leonard Lawlor. Illinois: Northwestern University Press.

Merleau-Ponty, M. (2009). O visível e o invisível. São Paulo: Ed. Perspectiva (Original publicado em 1964).

Merleau-Ponty, M (2010). L'Oeil et l'Espirit. Paris: Gallimard (Original publicado em 1960).

Moreira, V. (2004). O Método Fenomenológico de Merleau-Ponty como Ferramenta Crítica na Pesquisa em Psicopatologia. Psicologia: Reflexão e Crítica, 17(3), 447-456.

Moreira, V. \& Bloc, L. (2012). Clínica do Lebenswelt (mundo vivido): articulação e implicação entre teoria e prática. Em: Arthur Tatossian, \& Virginia Moreira. Clínica do Lebenswelt. Psicoterapia e psicopatologia fenomenológica (p. 285-297). São Paulo: Escuta.

Rodrigues Jr, O. M. (2001). Disfunção Erétil. São Paulo: Expressão e Arte Editora.

Fabiana De Zorzi - Gestalt-Terapeuta. Graduada em Psicologia pela Universidade de Caxias do Sul-RS (UCS) e Mestre em Psicologia Clínica pela Universidade de Fortaleza (Unifor). Membro efetivo (gestão 2013/2016) do Instituto de Psicologia Humanista e Fenomenológica do Ceará (IPHe). Foi membro efetivo do Centro de Estudos em Gestalt-Terapia-RS (gestão 2006-2007). E-mail: contato@fabianadezorzi.com

Georges Daniel Janja Bloc Boris - Psicólogo, Mestre em Educação e Doutor em Sociologia pela Universidade Federal do Ceará, Professor titular do Curso de Psicologia e do Programa de Pós-Graduação em Psicologia da Universidade de Fortaleza (Unifor). Coordenador do Laboratório de Psicopatologia e Psicoterapia Humanista-Fenomenológica Crítica - APHETO. Endereço Institucional: Universidade de Fortaleza, Programa de Pós-Graduação em Psicologia. Avenida Washington Soares, 1321 (Bairro Edson Queiroz). CEP: 60.811-905, Fortaleza, CE. E-mail: geoboris@uol.com.br 